\title{
RESEARCH
}

\section{Reliability of disclosure forms of authors' contributions}

\author{
Vesna Ilakovac, Kristina Fister, Matko Marusic, Ana Marusic
}

\section{ABSTRACT}

Background: The contribution disclosure forms used by medical journals to assess and confirm authorship are surveys of self-reported behaviour that follow the cognitive rules of psychometric instruments. We sought to analyze how autobiographical memory, defined as memory for events and issues related to oneself, affected the reliability of contribution forms for the judging of authorship of research articles.

Methods: We conducted a prospective study, which ultimately included 919 authors of 201 articles submitted to a general medical journal from July 2001 through December 2002. A authorship disclosure form with a checklist of 11 possible contribution choices for all authors was sent first to each article's corresponding author, who was asked to fill it out for all authors. A blank form was then sent to each author individually to disclose his or her own contribution to that article. The main outcome measure was test-retest differences between the corresponding authors' self-declarations, expressed in percent as the gross difference rate (GDR) for each article.

Results: More than two-thirds of the corresponding authors $(69.7 \%)$ differed in at least 1 contribution choice between the 2 disclosure statements made about their own contributions. The reliability of their answers was low to moderate (GDRs > 10\%), especially for contributions on the provision of study materials or patients or final approval of the article (GDR 22.9\%), guarantor of the study (GDR 20.9\%) and drafting of the manuscript (GDR $20.4 \%$ ). As a proxy for their coauthors' contributions, corresponding authors also differed from them in the perception of noncorresponding authors' contributions, disagreeing in $69.4 \%$ of cases. Of the 718 noncorresponding authors, 204 (28.4\%) met all the criteria for authorship set out by the International Committee of Medical Journal Editors according to the statement given by the corresponding author. When they described their own contributions, this prevalence increased to $40.5 \%$.

Interpretation: Psychological factors such as autobiographical memory may confound contribution disclosures as an evaluation tool for authorship on scientific articles and affect responsible authorship and publication practices.

CMAJ 2007;176(I):4I-6

A uthorship of scientific articles is the main measure of research productivity and an important requirement for academic advancement. ${ }^{1}$ It is nonetheless burdened with problems, such as misconceptions about ownership of research ${ }^{2}$ and misuse of author's responsibilities. ${ }^{3,4}$ To address undeserved claims of authorship and increase the transparency of scientific publishing, many journals have introduced the practice of contribution disclosure, whereby authors are required to fill out a contribution and authorship statement form. ${ }^{5}$ Contribution disclosure forms for assessing authorship are also surveys of self-reported behaviour and thus follow the same cognitive rules as other questionnaires. When answering a question, a participant in a survey performs 5 cognitive tasks: ${ }^{5}$ understanding the question, recalling relevant behaviour, inferring and estimating the behaviour in question, mapping the answer to the response format, and "editing" the answer for social desirability.

In a previous study, ${ }^{6}$ we showed that the introduction of contribution disclosure practices in 3 major medical journals was paralleled by differences in the prevalence of authors who did not satisfy the standardized authorship criteria of the International Committee of Medical Journal Editors (ICMJE). ${ }^{7}$ In a randomized study ${ }^{8}$ published in the Croatian Medical Journal, a general medical journal, we demonstrated as well that the structure of the contribution disclosure form influenced the number of contributions reported by authors of submitted manuscripts and their compliance with the ICMJE authorship criteria. This confirmed that the cognitive task of mapping the answer to the response format of the contribution disclosure form influences the answers on the forms and therefore the attribution of authorship as defined by ICMJE.

To test how the construct of autobiographic memory, defined as a personal representation of general or specific events and personal facts, ${ }^{9}$ affects the reproducibility of statements about contributions to a submitted article indicated on forms that self-report past behaviour, we carried out a study in which we asked the corresponding authors to report their contributions to the same article on 2 different occasions: first on the contributions of all coauthors (i.e., acting as a proxy on their behalf) and later, when all authors were sent the same (blank) form, as an individual asked to declare his or her own contribution as a coauthor.

\section{Methods}

All manuscripts submitted to the Croatian Medical Journal, an international general medical journal published in Croatia, ${ }^{8,10}$ were considered eligible for the study. All articles submitted from July 200I through December 2002 were considered $(n=318)$, although those without multiple authors 
(I2.3\%) were excluded (Fig. I). The final sample comprised 20I research articles with 2 or more authors and a total of 919 coauthors, with a median number of coauthors per article of 4 (95\% confidence interval [CI] 4-5; Table I). Upon receipt of each submitted article, a number of authorship forms equal to the number of authors of the manuscript was sent to the corresponding author. Each form (Appendix I, available at www.cmaj.ca/cgi/content/full/I76/I/4I/DCI) presented II possible contribution choices for declaration of authorship. Four to 6 weeks later, after these "group" forms were returned by the corresponding authors, the same (blank) form was sent to each coauthor (including the corresponding author) individually. To increase the return rate of the authorship forms, no authors were informed of any editorial decisions about their manuscript before the return of all forms sent in the second survey.

All correspondence with authors was in English, the official language of the journal. The authorship statement form had a general statement on editorial research that did not disclose the study aim or details but asked for consent to participate in general journalistic research (see the supplementary material in section 5 of the form). The Ethics Com-

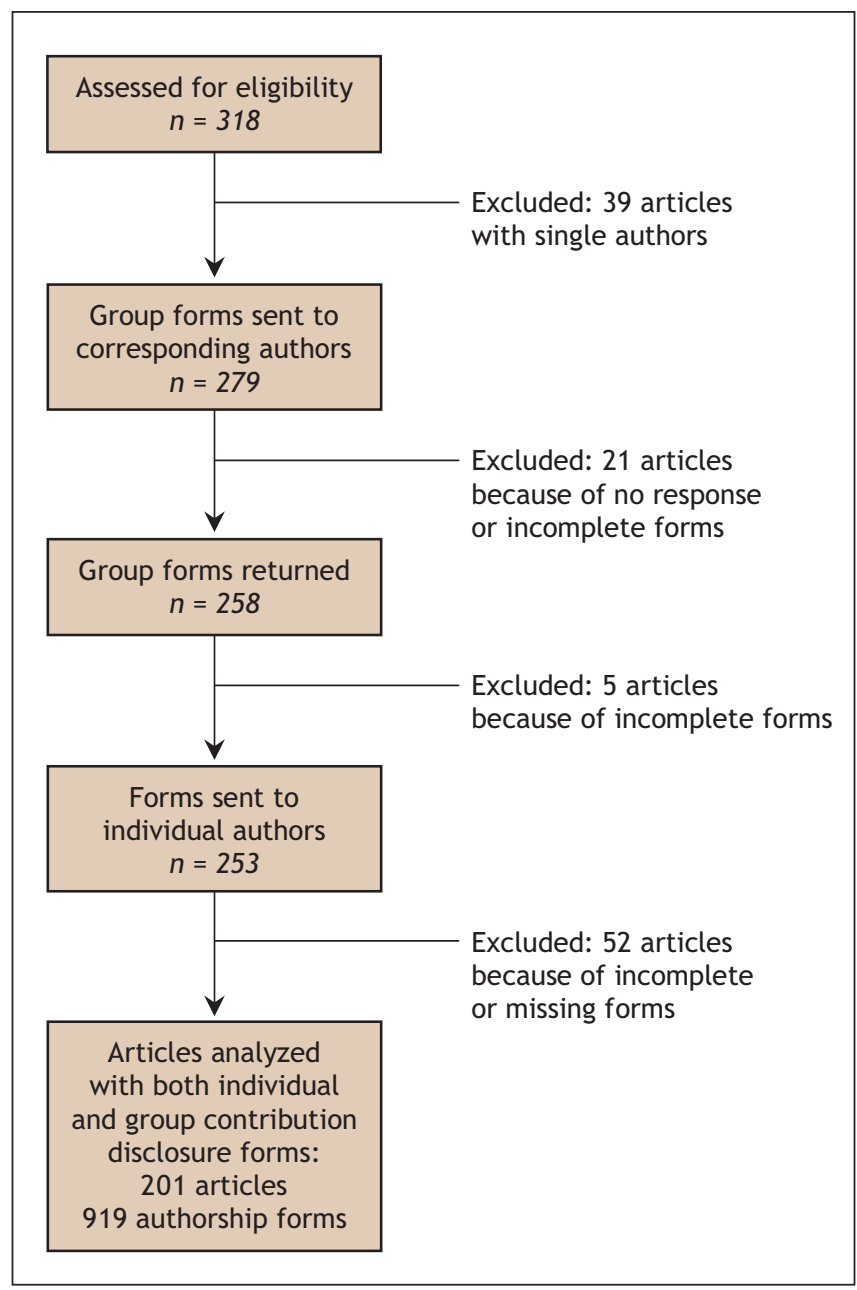

Fig 1: Flowchart showing the study exclusions that led to the final sample size. mittee of the Osijek University School of Medicine gave ethical approval for the study.

The authorship form (Appendix I, at www.cmaj.ca/cgi /content/full/I76/I/4I/DCI) had an introductory paragraph describing the authorship criteria of $\mathrm{ICMJE}^{7}$ and emphasized that the Croatian Medical Journal follows these criteria. The list of II contribution choices were ordered randomly with use of a random number generator, as follows: (I) participation in the conception and design of the study; (2) analysis and interpretation of data; (3) provision of study material or patients; (4) collection, assembly and possession of the raw data; (5) statistical expertise; (6) drafting of the article; (7) critical revision of the manuscript for important intellectual content; (8) final approval of the article for publication; (9) obtaining funding for the study; (Io) administrative, technical or logistical support; and (II) willingness to guarantee the integrity of the entire study.

The Ist, 2nd, 4th or $5^{\text {th }}$ contribution choices constituted eligibility for authorship in accordance with the first ICMJE criterion (conception and design of the study or data acquisi-

\begin{tabular}{|c|c|c|}
\hline Variables & No.* & $\%^{*}$ \\
\hline \multicolumn{3}{|l|}{ Geographical origin of study } \\
\hline Croatia & 121 & 60.2 \\
\hline From the rest of the world ( 24 countries) & 80 & 39.8 \\
\hline \multicolumn{3}{|l|}{ Type of affiliated institution, $n=155$} \\
\hline Academic or health & 84 & 54.2 \\
\hline Research or other & 71 & 45.8 \\
\hline Affiliated institutions per article, median no. $(95 \% \mathrm{Cl}$ & 2( & 1-2) \\
\hline \multicolumn{3}{|l|}{ Field of research } \\
\hline Clinical sciences & 107 & 53.2 \\
\hline Basic sciences & 39 & 19.4 \\
\hline Public health & 40 & 19.9 \\
\hline Other & 15 & 7.5 \\
\hline \multicolumn{3}{|l|}{ Type of article } \\
\hline Original research & 173 & 86.1 \\
\hline Review article & 8 & 4.0 \\
\hline Case report & 20 & 10.0 \\
\hline Authors per article, median no. $(95 \% \mathrm{Cl})$ & & $(4-5)$ \\
\hline \multicolumn{3}{|l|}{ Corresponding author's "authorship rank" } \\
\hline First author & 162 & 80.6 \\
\hline In middle; i.e., amidst multiple authors & 19 & 9.5 \\
\hline Last author & 20 & 10.0 \\
\hline \multicolumn{3}{|l|}{ Declared contribution items, total no. } \\
\hline In group authorship declaration forms & 3552 & \\
\hline In individual forms & 4157 & \\
\hline \multicolumn{3}{|l|}{ Contributions per author, median no. $(95 \% \mathrm{Cl})$} \\
\hline In group forms & \multicolumn{2}{|c|}{$3(3-4)$} \\
\hline In individual forms & \multicolumn{2}{|c|}{$4(4-4)$} \\
\hline
\end{tabular}

Note: $\mathrm{Cl}=$ confidence interval.

*Unless otherwise indicated. 
tion or analysis and interpretation) of the Uniform Requirements for Manuscripts Submitted to Biomedical Journals; ${ }^{7}$ the 6th or 7 th, in accordance with the second criterion (manuscript drafting or revision); and the 8th, with the third criterion (final approval). The authorship of anyone whose contributions did not meet all 3 ICMJE criteria (i.e., those who disclosed only the $3 \mathrm{rd}$, 9th, Ioth or Ith choices) was deemed to be honorary. Satisfaction of ICMJE authorship criteria was evaluated for all authors according to statements returned in either survey.

We measured test-retest differences in the contribution choices indicated by corresponding authors as the gross difference rate (GDR) ${ }^{11}$ for that article. The differences between individual coauthors' declarations and those made on their behalf by the corresponding authors were expressed as differences in proportions of group and individual forms.

Differences in proportions of variables between the group and individual forms were tested with the exact McNemar test. Differences in the total number of authors' contributions stated on group and individual forms were tested with the Wilcoxon signed-rank test (S). Differences in the median number of byline authors between subgroups of articles (those with and without honorary authors) were tested with the MannWhitney U test. GDR was used to assess the reliability of answers given by corresponding authors about their own contributions. ${ }^{11}$ It was calculated as GDR $=100 \times(b+c) / n$, where $(b+c)$ represents the sum of the off-diagonal frequencies in the cross-tabulation table of the test-retest answers. Reliability was considered high (GDR < I0\%), moderate (GDR 10\%$20 \%$, boundaries included) or low (GDR $>20 \%$ ). ${ }^{11}$ All $p$ values were 2-tailed; a Bonferroni correction was used for subgroup comparisons.

\section{Results}

When we compared the contribution choices made at 2 different times by the corresponding authors on the same type of form for the same article, we found that more than twothirds (I40/20I, 69.7\%) differed in at least one contribution choice. The most consistent choice was "conception and design of the study" (Table 2): only 8 of 2or test-retest pairs differed in the declaration on the category, considered highly reliable (GDR $4.0 \%$, 95\% CI $2.0 \%-7.7 \%$ ). The reliability of other contribution choices was medium to low. Among the choices eligible for ICMJE authorship criteria, the lowest reliability was observed for the category "final approval of the article," followed by "drafting of the article" and "critical revision of the manuscript for important intellectual content" (Table 2). Interestingly, corresponding authors were unsure about their own contributions to the provision of study materials or patients, which had the lowest reliability (GDR $22.9 \%, 95 \%$ CI $17.6 \%-29.2 \%)$.

Declaration choices made by the corresponding authors for their coauthors also differed from those made by the coauthors for themselves (Table 2). Coauthors chose more contribution categories on individual authorship forms than corresponding authors did for them on group forms $(S=42578.5 ; p<0.001$; Table 3). Corresponding author and coauthors also disagreed on at least one choice for coauthor contributions in 498 of 718 cases $(69.4 \%)$, although they agreed consistently on 3 contribution choices: "drafting of the article," "obtaining funding" and "administrative, technical or logistical support" (Table 2). "Final approval of the article" was the category with the largest observed difference in prevalence between the declarations provided by the corresponding author for all authors than

Table 2: Test-retest differences in the contribution choices of corresponding authors and rates of contribution choices on group and individual disclosure forms for noncorresponding authors.

\begin{tabular}{|c|c|c|c|c|c|}
\hline \multirow{3}{*}{$\begin{array}{l}\text { Contribution to article, in survey order } \\
\text { of choices }\end{array}$} & \multirow{3}{*}{$\begin{array}{l}\text { ICMJE } \\
\text { criterion* } \\
\text { fulfilled } \\
\text { by choice }\end{array}$} & \multirow{3}{*}{$\begin{array}{l}\text { Corresponding authors, } \\
n=201 \\
\text { Gross difference } \\
\text { rate, } \%(95 \% \mathrm{Cl}) \dagger\end{array}$} & \multicolumn{3}{|c|}{ Noncorresponding authors, $n=718$} \\
\hline & & & \multicolumn{2}{|c|}{$\%$ of forms } & \multirow{2}{*}{$\begin{array}{l}\text { Difference, \% } \\
\quad(95 \% \mathrm{Cl})\end{array}$} \\
\hline & & & Individual & Group & \\
\hline 1 Conception and design of the study & I & $4.0 \quad(2.0$ to 7.7$)$ & 42.9 & 36.5 & 6.4 (3.4 to 9.4$)$ \\
\hline 2 Analysis and interpretation of data & I & 12.4 (8.6 to 17.7$)$ & 55.0 & 48.1 & 6.9 (3.6 to 10.3$)$ \\
\hline 3 Provision of study material or patients & - & 22.9 (17.6 to 29.2 ) & 43.9 & 37.5 & 6.4 (2.9 to 9.9$)$ \\
\hline 4 Collection, assembly, possession of raw data & I & 14.9 (10.7 to 20.5$)$ & 48.5 & 39.7 & $8.8(5.4$ to 12.1$)$ \\
\hline 5 Statistical expertise & I & $12.9 \quad(9.0$ to 18.3$)$ & 17.3 & 13.2 & 4.1 (1.8 to 6.3$)$ \\
\hline 6 Drafting of the article & II & 20.4 (15.4 to 26.5$)$ & 30.6 & 28.1 & $2.5(-0.5$ to 5.5$)$ \\
\hline $\begin{array}{l}7 \text { Critical revision of the article for important } \\
\text { intellectual content }\end{array}$ & II & 20.4 (15.4 to 26.5$)$ & 52.8 & 44.0 & $8.8(5.2$ to 12.3$)$ \\
\hline 8 Final approval of the article & III & 22.9 (17.6 to 29.2$)$ & 50.6 & 36.2 & $14.4(10.9$ to 17.7$)$ \\
\hline 9 Obtaining funding for the study & - & 16.9 (12.4 to 22.7$)$ & 9.9 & 8.4 & $1.5(-0.5$ to 3.6$)$ \\
\hline 10 Administrative, technical or logistical support & - & 20.4 (15.4 to 26.5$)$ & 24.7 & 23.0 & $1.7(-1.4$ to 4.7$)$ \\
\hline 11 Guarantor of integrity of the entire study & - & 20.9 (15.8 to 27.0$)$ & 20.8 & 14.3 & 6.5 (4.0 to 8.9$)$ \\
\hline
\end{tabular}

Note: ICMJE = International Committee of Medical Journal Editors, $\mathrm{Cl}=$ confidence interval.

*One of the 3 criteria for article authorship as defined by the International Committee of Medical Journal Editors in their Uniform Requirements for Manuscripts Submitted to Biomedical Journals, as follows: I = substantial contributions to conception and design, or acquisition of data, or analysis and interpretation of data; II = drafting the article or revising it critically for important intellectual content; III = final approval of the version to be published.

$\dagger$ Between contribution choices as reported by corresponding authors at the 2 survey times. 
those made individually by each author (difference $14.4 \%, 95 \%$ CI I0.9\%-I7.7\%; $p<0.001$ ).

Although individual declarations reported a greater variety of contribution choices (i.e., more choices in total) than those filled out by corresponding authors on group forms (Table I), the number of articles in which all coauthors satisfied all 3 ICMJE criteria for authorship did not increase significantly (difference $4 \%, 95 \% \mathrm{CI}-2 \%$ to I0\%; $p=0.24$; Table 3). Neither was there any significant difference in the prevalence of honorary authors on articles from Croatia or other countries (range $7 \mathrm{I} \%-77 \%$ ), regardless of who filled out the contribution form.

Of the 607 honorary authors defined according to the group forms, I6I (26.5\%) met all ICMJE criteria when they filled out their individual form. Conversely, of 312 authors who met all ICMJE criteria according to group forms, 48 (I5.4\%) failed to meet them on their individual forms. In a total of $64(31.8 \%)$ of 201 articles, all authors listed on the by- line were honorary authors according to the statements given by corresponding authors. When authors themselves described their own contributions, this prevalence decreased to $20 \%$ (difference $-\mathrm{I} 2 \%, 95 \% \mathrm{CI}-\mathrm{I} 8 \%$ to $-6 \%$; $p<0.00 \mathrm{I}$ ). According to either statement, about $25 \%$ of all articles had no honorary authors listed in the byline (Table 3). Articles with honorary authors had significantly longer bylines then those without honorary authors according to either type of form $(z$ $=-2.837$ for group forms, $p=0.005 ; z=-3.674$ for individual forms, $\mathrm{p}<\mathrm{0.00I}$ ).

When we matched the declared contribution of corresponding authors on either form against the ICMJE criteria, we found that these criteria were satisfied to a greater extent according to the individual than group contribution form (difference $13 \%, 95 \%$ CI 6\%-20\%; $p=0.00 I$; Table 3). Of the $7 \mathrm{I} 8$ noncorresponding authors, $28.4 \%$ fully met the ICMJE criteria for authorship according to the statements given by corresponding authors. When they themselves described their own

Table 3: Honorary authorship* of 201 articles submitted to a general medical journal, according to whether the contribution disclosure form was filled out by the corresponding author for all authors (group) or by each individual author.

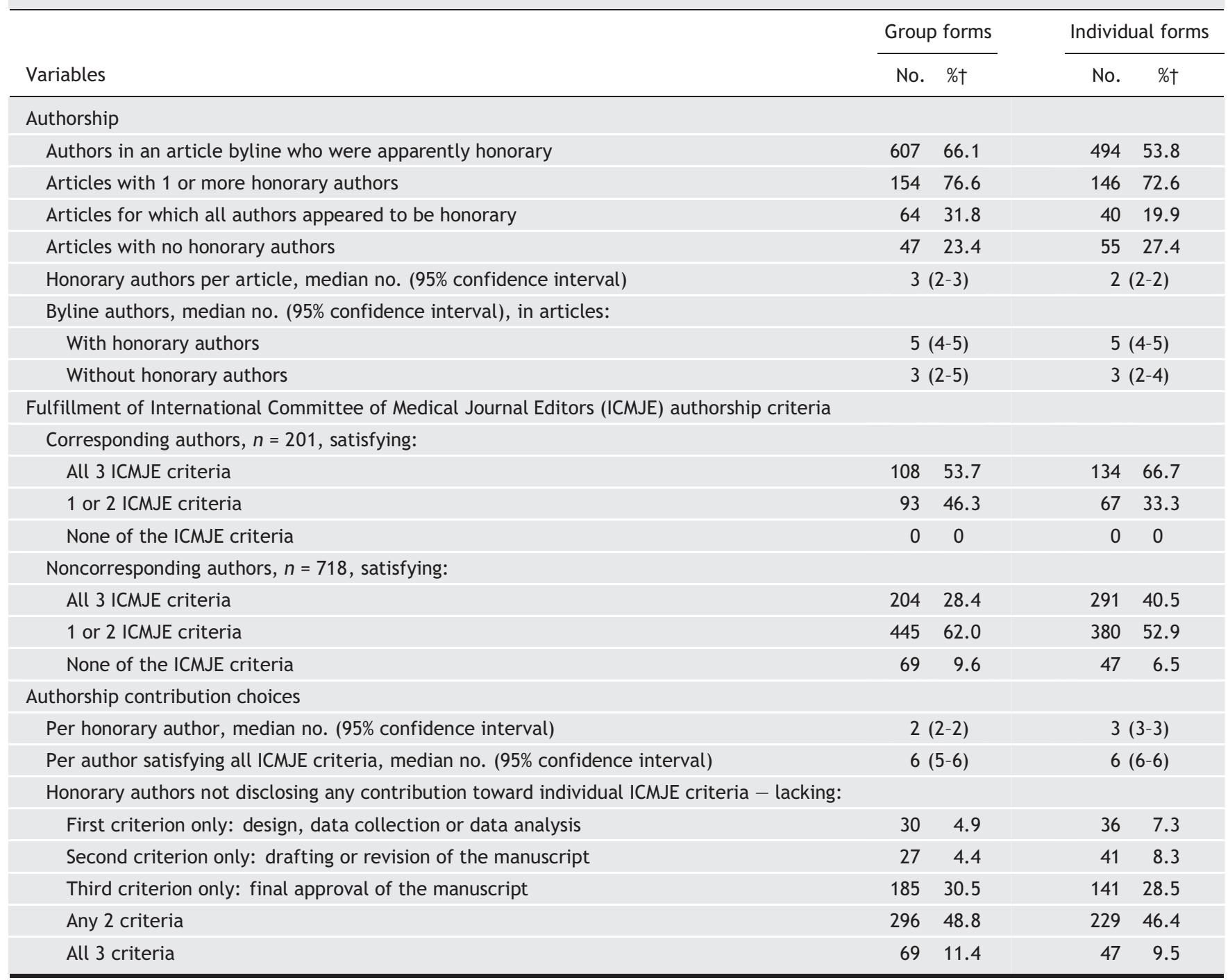

*Attributed to any person listed in the byline who did not satisfy all 3 ICMJE criteria for authorship of that article.

†Unless otherwise specified. 
contributions, this prevalence increased to $40.5 \%$ (difference I $2.1 \%, 95 \%$ CI $8.8 \%-15.4 \% ; p<0.00 \mathrm{I})$.

Among honorary authors who missed I out of the 3 ICMJE criteria, it was the third (final approval of the article) for almost half of them, whether the information came from group or individual forms (Table 3). In combination with the other 2 , this criterion was missed by $88.8 \%$ of the honorary authors on the group and $83.0 \%$ of honorary authors on their individual contribution form. Honorary authors mostly missed any 2 of the 3 ICMJE criteria; among those who missed all 3, none were corresponding authors.

\section{Interpretation}

Our study showed that the autobiographical memory construct, the memory for events and issues related to oneself, ${ }^{9}$ is involved in the cognitive aspect of filling out contribution declaration forms and confounds the conclusions about selfreported contributions toward the authorship of scientific articles, as well as their reliability. In psychometric terms, reliability is defined as the extent to which a test is dependable, stable and consistent when administered to the same people on different occasions. ${ }^{5}$ The existence of significant discrepancies between declarations made at 2 different times by corresponding authors about their own work on a single manuscript suggests that they had problems recalling relevant events from memory.

Research into retrieval of autobiographical memory shows that activities are the best retrieval cues, followed by location of and participants in the event. ${ }^{12}$ Because the work on a manuscript to be submitted to an academic journal is an important part of being a scientist, ${ }^{13}$ such events should be well represented in memory and recalled easily. Moreover, the period between the 2 surveys in our study (4-6 weeks) should not have influenced the accuracy of memory, since both surveys were sent well after the stabilization of memory that occurs after its initial detrition. ${ }^{14}$ The fact that corresponding authors, presumably the people most knowledgeable about their manuscripts, did not consistently report on their own past behaviour may mean that the behaviours related to the article were poorly represented in memory or that they did not fill out the contribution disclosure forms truthfully, editing one or both for social desirability. ${ }^{5}$ Testing these possible explanations would require experimental settings not possible within the framework of editorial communication with authors. However, available theoretical and experimental data, ${ }^{5}$ coupled with the well-known pressure to publish among scientists, ${ }^{13}$ favour the second explanation of self-editing for social desirability.

Our study confirmed that reports about others' behaviours, such as proxy reports on the contributions of one's coauthors, were not an accurate way of assessing authorship. As has been shown by well-controlled experimental psychological observations, ${ }^{5}$ proxy reports about behaviours of others are burdened by a subjective inference process in estimating behaviour. Proxy observers base their reports largely on their assumptions about that person, rather than on their memory of the event. They may not be fully aware of others' behaviour, and unless it was extreme or memorable, this behaviour is usually not well represented in their memory. ${ }^{5}$

Our study is limited by its survey design, but our findings are strengthened by a very high response rate, since filling out authorship forms is mandatory for manuscript processing in most science journals. Generalizability of the findings to other medical journals and research and academic settings can also be questioned. However, the results were not likely influenced by the type or quality of the journal, because we primarily studied how people reported on their behaviour and not the practices in a specific journal. Research in this area of psychology has been performed in different settings and cultural environments, with consistent results. ${ }^{5}$ Respondents from our study came from different settings, and the findings did not differ among manuscripts from different geographical regions.

Psychometric analysis of contribution disclosure reports has indicated that they are an unreliable source of information. The present study, which addressed recalling relevant behaviour when answering a self-report, and our previous study showing that the form of asking questions shapes the contribution declaration ${ }^{8}$ provide evidence that the contribution declaration and the authorship criteria themselves have been introduced into the scientific-publication process without adequate evidence for all aspects of their validity.

As journal editors we need much more evidence to assume the right to judge or regulate ${ }^{15}$ matters of authorship, which primarily belongs to the wider academic and research communities. ${ }^{16}$ Although surveys show that researchers often do not agree with the ICMJE criteria or even know what they are, ${ }^{13}$ intervention studies have shown that a simple instruction given to medical students improves their knowledge and use of ICMJE authorship criteria. ${ }^{17}$ Contributorship statements can be prospectively drafted and revisited before manuscript submission to the satisfaction of all stakeholders in a research project. ${ }^{18}$ Offering a Likert-style quantification scale as a reference for author's contributions instead of the usual yes/no checkboxes might increase the number of contributors deserving authorship status. ${ }^{19}$ Until there is enough evidence to propose fair, universal and reliable guidelines for authorship, perhaps the editors should ask all authors a simple, open-ended question: "Why do you think you deserve to be the author of this manuscript?"

\section{This article has been peer reviewed.}

From the Department of Medical Statistics and Medical Informatics (Ilakovac), School of Medicine, Josip Juraj Strossmayer University, Osijek; and the Andrija Stampar School of Public Health (Fister) and Croatian Medical Journal (M. Marusic, A. Marusic), Zagreb University School of Medicine, Zagreb, Croatia.

Competing interests: None declared. Ana Marusic and Matko Marusic are coeditors-in-chief of the Croatian Medical Journal, for which they receive no fee.

Contributors: Ana Marusic and Matko Marusic conceived of and designed the study. Vesna Ilakovac, Kristina Fister and Ana Marusic analyzed and interpreted the data. Ana Marusic and Vesna Ilakovac drafted the paper and Kristina Fister and Matko Marusic critically revised it for important intellectual content. All authors gave final approval of the version to be published. 
Acknowledgement: The study was supported by a research grant from the Ministry of Science and Technology of the Republic of Croatia (grant no. oI08182). The sponsor had no role in the study.

The results of this study were presented in part at the Fifth International Congress on Peer Review and Biomedical Publication, Chicago, Ill., 2005 Sept. I6-I8.

\section{REFERENCES}

I. Pololi L, Knight S, Dunn K. Facilitating scholarly writing in academic medicine. J Gen Intern Med 2004;19:64-8.

2. Fields KL, Price AR. Problems in research integrity arising from misconceptions about the ownership of research. Acad Med I993;68 (9 Suppl):S6o-4.

3. Claxton LD. Scientific authorship. Part I. A window into scientific fraud? Mutat Res 2005;589:17-30.

4. Davidoff F, DeAngelis KD, Drazen JM, et al. Sponsorship, authorship and accountability. CMAJ 200I;165(6):786-7.

5. Schwarz N, Oyserman D. Asking questions about behaviour: cognition, communication, and questionnaire construction. Am JEval 200I;22:127-60.

6. Bates T, Anic A, Marusic M, et al. Authorship criteria and disclosure of contributions - comparison of 3 general medical journals with different author contribution forms. JAMA 2004;292:86-8.

7. International Committee of Medical Journal Editors. Uniform requirements for manuscripts submitted to biomedical journals: writing and editing for biomedical publication. Available: www.icmje.org (accessed 2006 Oct I9).

8. Marusic A, Bates T, Anic A, et al. How the structure of contribution disclosure statement affects validity of authorship: randomized study in a general medical journal. Curr Med Res Opin 2006;22:1035-44.

9. Robinson JA. Autobiographical memory. In: Gruneberg M, Morris P, editors. As pects of memory. Vol. I. The practical aspects. 2nd ed. London: Routledge; 1992.
Io. Marusic M, Sambunjak D, Marusic A. Life of small medical journal - how bibliographical indexing and international visibility affected editorial work in the Croatian Medical Journal. Croat Med J 2006;47:372-5.

II. Forsman G, Schreiner I. The design and analysis of reinterview: an overview. In: Biemer PP, Groves RM, Lyberg LE, et al., editors. Measurement errors in surveys. New York: John Wiley \& Sons; 2004.

I2. Burt CDB. Retrieval characteristics of autobiographical memories: event and date information. Appl Cogn Psychol 1992;6:389-404.

I3. Bhopal R, Rankin J, McColl E, et al. The vexed question of authorship: views of researchers in a British medical faculty. BMJ I997;3I4:1009-I2.

I4. Friedman WJ, deWinstanley PA. Changes in the subjective properties of autobiographical memories with the passage of time. Memory i $998 ; 6: 367-8 \mathrm{I}$.

I5. Brice J, Bligh J. Author misconduct: not just the editors' responsibility. Med Educ 2005;39:83-9.

I6. Marusic A, Marusic M. Killing the messenger: should scientific journals be responsible for policing scientific fraud? Med J Aust 2006;184:596-7.

I7. Hren D, Sambunjak D, Ivanis D, et al. Perceptions of authorship criteria: effects of student instruction and scientific experience. JMed Ethics. In press.

I8. Devine EB, Beney J, Bero LA. Equity, accountability, transparency: implementation of the contributorship concept in a multi-site study. Am J Pharm Educ 2005;69: 455-9.

I9. Ivanis A, Hren D, Misak A, et al. Quantification of authors' contributions and eligibility for authorship: a randomized trial [abstract]. Proceedings of the 5 th International Congress on Peer Review and Biomedical Publication; 2005 Sept 16-18; Chicago: Peer Review Congress; 2005.

Correspondence to: Dr. Ana Marusic, Zagreb University School of Medicine, Salata 3, HR-Ioooo Zagreb, Croatia; fax oII 385 I 459 o222; marusica@mef.hr

Proceedings of the National Microbiology Laboratory Pertussis Workshop, 32S4 November 2006

Canadian National Report on Immunization, 2006, 32S3 November 2006

Guidelines for the Prevention and Control of Invasive Group A Streptococcal Disease, 32S2 October 2006

Canadian Human Papillomavirus Vaccine Research Priorities Workshop Final Report, 32S1 July 2006

Guidelines for the Prevention and Control of Meningococcal Disease, 31S1 May 2005

2002 Canadian Sexually Transmitted Infections Surveillance Report, 31S2 June 2005

Management of Patients with West Nile Virus: Guidelines for Health Care Providers, 31S3 December 2005

To obtain additional copies or subscribe, contact: Canadian Medical Association, Member Service Centre

Outside Ottawa

Ottawa and area

Email
$888855-2555$

$613731-8610 \times 2307$

cmamsc@cma.ca

Compte rendu de l'atelier sur la coqueluche du laboratoire national de microbiologie, 32S4 novembre 2006

Rapport national sur l'immunisation au Canada, 2006, $32 S 3$ novembre 2006

Lignes directrices pour la prévention et le contrôle de la maladie invasive due au streptocoque du groupe A, 32S2 octobre 2006

Atelier sur les priorités canadiennes en matière de recherche sur les vaccins contre le virus du papillome humain Rapport Final, $32 S 1$ juillet 2006

Lignes directrices pour la prévention et la lutte contre les atteintes méningococciques, $31 S 1$ mai 2005

Rapport de surveillance canadien 2002 sur les infections transmises sexuellement, 31 S2 juin 2005

Prise en charge des patients infectés par le virus du Nil occidental : Lignes directrices à l'intention des professionnels de la Santé , 31S3 décembre 2005

Renseignements au sujet des prix et commandes Association médicale canadienne, Centre des services aux membres

De l'extérieur d'Ottawa :

Ottawa et la région :

Courriel :
888 855-2555

$613731-8610$ poste 2307 cmamsc@cma.ca 